\title{
A dynamical approach for the uptake of radionuclides in marine organisms for the POSEIDON model system
}

\author{
R. Heling, L. Koziy ${ }^{1}$ and V. Bulgakov ${ }^{2}$ \\ NRG, P.O. Box 9035, ET Arnhem, The Netherlands \\ ${ }^{1}$ IMMSP, Glushkova Pr. 42, 03187 Kiev, Ukraine \\ 2 SPA "Typhoon", Lenin Str. 82, 249020 Obninsk, Russia
}

\begin{abstract}
.
The existing POSEIDON compartment model, developed for modelling the dispersion of radionuclides in coastal areas for regular discharges was modified to be applicable in accidental conditions. One of the important modifications was the development of a generic uptake model for marine organisms to deal with short pulses of radionuclides after accidental releases in the coastal environment. A generic foodweb model to be used in the decision support system POSEIDON-R has been developed. Six key organisms represent the different trophic levels with identical physiological properties. To avoid the introduction of different compartments for the several organs in which radionuclides can accumulate, the so-called target tissue approach was followed. It is assumed that each radionuclide accumulates in a single specific tissue, (the key tissue), and that the behaviour of this radionuclide is organ- and not radionuclide-dependent. To test the reliability of this model, validation tests for various regions, and for several radionuclides, are required. Tests for the Baltic Sea and the Black Sea for the period after the Chernobyl accident in 1986 demonstrated a rather good agreement with the measured data on radiocaesium. The model gave in some cases an overestimation, which is not unacceptable for the aim of decision support.
\end{abstract}

\section{INTRODUCTION}

The current dose assessment models for evaluating discharges in coastal areas, such as MARINA [1], and CREAM [2], were developed for regular discharges. In the RODOS system, developed in the $3^{\text {rd }}$ and the $4^{\text {th }}$ Framework Program of the European Commission, a hydrological model set has been developed as part of the on-line decision support system RODOS [3]. For the short-term dispersion of radionuclides in estuaries and coastal areas, complex 2D and 3D models were added to the RODOS hydrological model set. For the long-term dispersion in the coastal environment, the existing POSEIDON [4] compartment model, developed for modelling the dispersion of radionuclides in coastal areas for regular discharges was modified to be applicable in accidental conditions. A large number of modifications was aimed to deal with short pulses of radionuclides - both from deposition and from transfer via rivers and run-off such as the introduction of more compartments for the European coastal waters, a vertical compartment structure, and flexible local discharge compartments. These modifications were made by using a 3D model - THREETOX-, as has been developed for the decision support system RODOS, has been used to find the necessary hydrodynamical parameters.

Due to the non-steady-state conditions after short pulses of radionuclides in the aquatic environment, the classic concentration factor approach is not sufficient to calculate the fate and behaviour of radionuclides in marine organisms. The reason is that the hydrological residence time in the smaller coastal compartments (of the POSEIDON model) is of the same order of magnitude or smaller than the retention time of radioactivity in marine organisms. This causes that equilibrium between fish and water will not be reached. Therefore a dynamical model BURN (Biological Uptake model of Radionuclides), has been developed, tested, and implemented into the POSEIDON model.

\section{THE UPTAKE MODEL BURN}

BURN is a dynamical model, developed to calculate the levels of radionuclides in the various trophic levels of the marine foodweb. Six different types of marine organisms represent the various types of marine organisms in the different trophic levels of the foodweb. The model takes into account both the uptake of radionuclides via food consumption by describing the predator-prey relations of the foodweb, and the direct uptake of radionuclides from the water via the gills (Figure 1). The behaviour of the radionuclides in the organisms is described by differential equations of the first order.

The retention time of a radionuclide in the aquatic organisms is a crucial model parameter in the model. Literature [6] shows a large variation for the retention time, or biological half-life, dependent on the radionuclide and the fish species. The tissue, in which the radionuclide accumulates, determines the biological half-life of the radionuclide in the entire organism. Therefore in the BURN model, the biological half-life of a radionuclide is related to the retention time of the radionuclide of the tissue. It is 
assumed that radionuclides accumulate in one of the four most important tissues -flesh, bones, organs, and intestines - each with its own retention time. BURN calculates the behaviour in this 'target tissue', assuming that the radioactivity in the other parts of fish is negligible compared with the concentration in the target tissue. By doing this, BURN becomes a tissue-instead of a radionuclide-based model [5]. The 'target tissue' approach, grouping the radionclides into four organ classes, in combination with a limited number of six key organisms, prevents the collection of a large amount of input parameters for each radionuclide and for each organism. This simplification is necessary when BURN is applied in real-time dose assessments tools for nuclear emergencies, such as the POSEIDON model, as a predictive model,

The most important radionuclide-specific input parameter of BURN is the Concentration Factor for marine phytoplankton. In the POSEIDON model, this parameter for BURN is based on generic literature values for marine phytoplankton [6]. In this validation study different values for the Concentration Factor for Cs-137 were tested, based on CF values for phytoplankton as reported in [7] to take into account the differences in salinity between the Baltic Sea and North Sea compartments of the POSEIDON model (Figure 2).

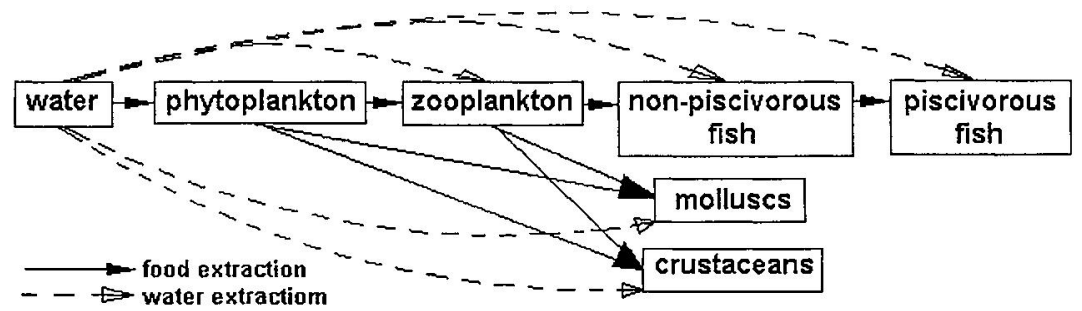

Figure 1. Radionuclide transfer to marine organisms

Figure 2. Scheme of the POSEIDON-R boxes.

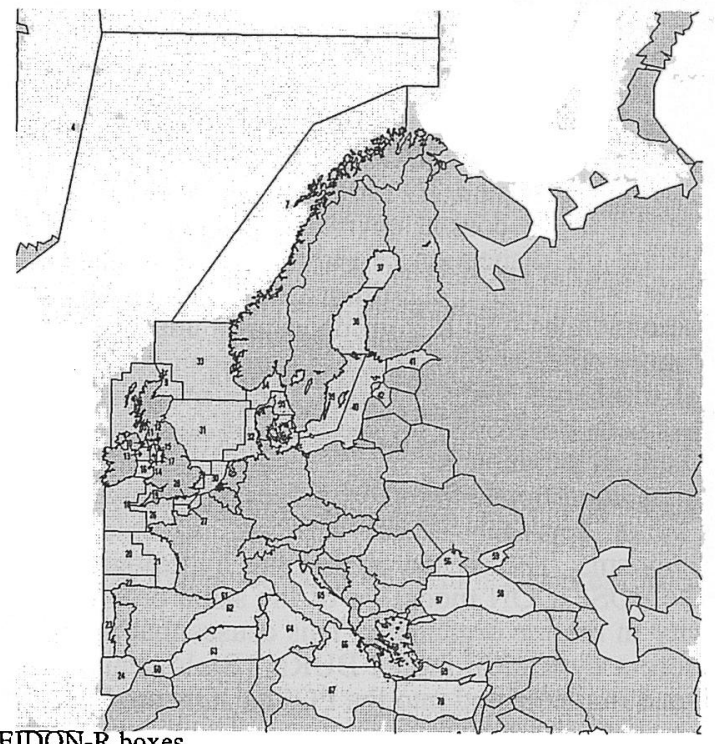

\section{APPLICATION OF THE MODEL BURN ON THE BALTIC SEA, ON THE BLACK SEA AND ON THE NORTH SEA}

The Chernobyl accident transferred radionuclides over long distances via rivers systems to the estuaries and coastal regions, and deposited radionuclides on the surface of the European coastal waters. This deposition of radionuclides differed strongly for the various European regions, coasts, and rivers. With POSEIDON the dispersion of radionuclides was reconstructed for three different regions of interest: the Black Sea, the Baltic Sea, and the North Sea. To reconstruct the radionuclide concentration in the coastal environment, time-series of radionuclide fluxes, both from rivers and from direct deposition, for the period 1950 up to 2000 were used. For these target areas the fluxes from the rivers and the deposition directly on the surface over the period $1950-2000$ were used as model input [5]. A detailed study on the Black Sca to reconstruct the radionuclide patterns over the years is performed by means of the $3 \mathrm{D}$-model 
THREETOX [5]. The model results of the POSEIDON model for the three seas were used as input for the BURN model. The aim was to investigate whether the approach of BURN could reconstruct the radionuclide concentration in marine organisms. Figure 1 gives an overview of the compartments of the POSEIDON model. Measurement data on radiocaesium were derived from studies on the Baltic Sea, MARINA-BALT- [8]; Black Sea and North Sea data were collected within the EC - project "POSEIDON" [5].

The non-radionuclide specific model parameters of the foodweb model BURN are based on the metabolism of the four different target tissues, and on standard values for growth rates and respiration rates, and on food and water extraction rates for the different marine organisms. In the application of BURN in the POSEIDON model, these parameters are considered as model constants. Values for the radionuclide-specific parameter of the BURN model, the concentration factor for phytoplankton, was derived from IAEA Tech Doc 247 [6]. However for radiocaesium a standard value for the CF of $5 \mathrm{~L} / \mathrm{kg}$ was selected from [7] where a value ranging between $0-5 \mathrm{~L} / \mathrm{kg}$ was reported for marine phytoplankton. To take into account the fact, that salinity suppresses the radionuclide uptake into phytoplankton, for the high salinity North Sea a lower value of $0.5 \mathrm{~L} / \mathrm{kg}$ was selected, while for the brackish Baltic Sea a CF value of $3.5 \mathrm{~L} / \mathrm{kg}$ was selected. For the Black Sea the standard value for the $\mathrm{CF}$ was not changed and kept on $5 \mathrm{~L} / \mathrm{kg}$, the default POSEIDON value.

\section{RESULTS}

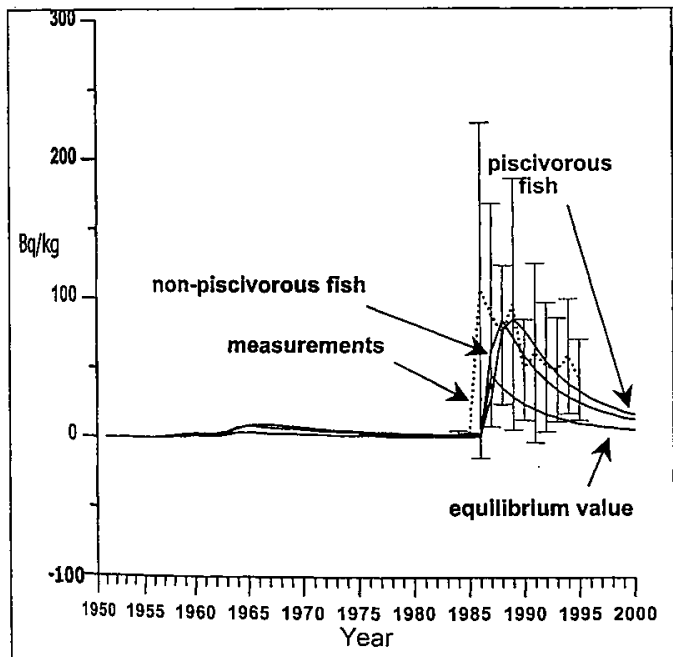

Figure 3. Bothnian Sea (box 38). Cs-137 concentration in fish. (Two-layered vertical structure, THREETOX exchange coefficients)

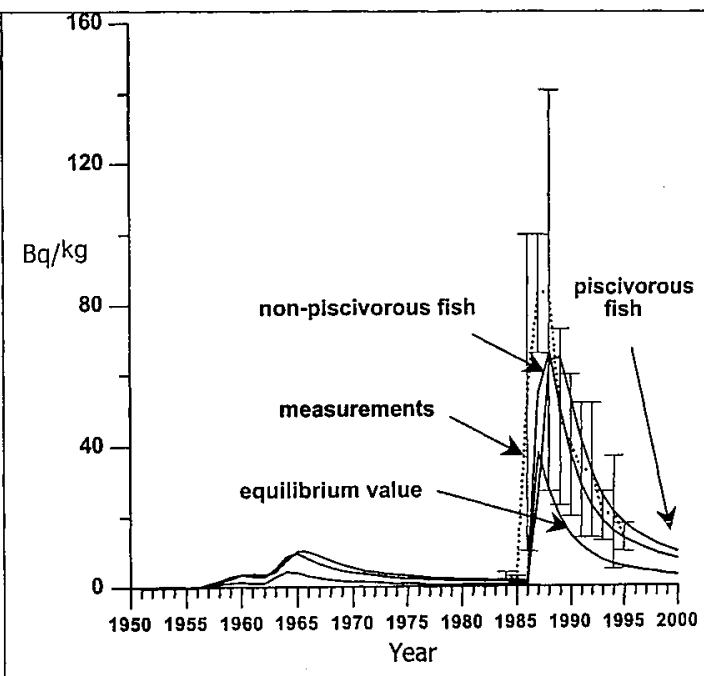

Figure 4. Gulf of Finland (box 41). Cs-137 concentration in fish. (Two-layered vertical structure, THREETOX exchange coefficients).

\footnotetext{
The model results for some of the compartments of the Baltic Sea are presented in figure $3-6$. Figure 3 and 4 presents the results for the Bothnian Sea, and for the Gulf of Finland respectively. The equilibrium values for predatory and non-predatory fish calculated by means of the classical CF method are compared with results of the dynamical food web model BURN. It is clearly demonstrated that the CF-method underpredicts the caesium levels in fish. Figure 5 and 6 present the comparison of the model results both with MARNA - BALT data and data supplied by SPA "Typhoon" for some specific fish species, pike and herring from the Baltic Sea. Model results for the other POSEIDON compartments are presented elsewhere [5].
} 


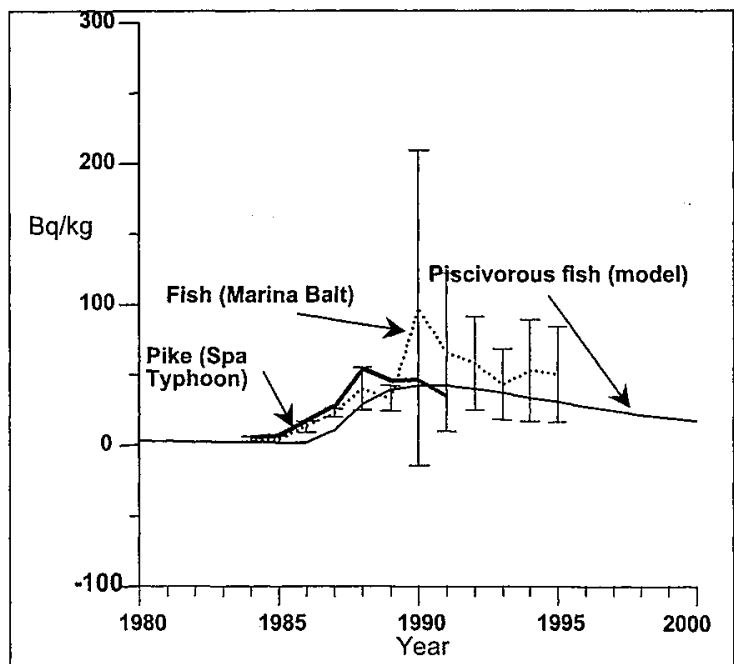

Figure 5. Bothnian Bay (box 37). Cs-137 Concentration in piscivorous fish. (Two-layered vertical structure, THREETOX exchange coefficients).

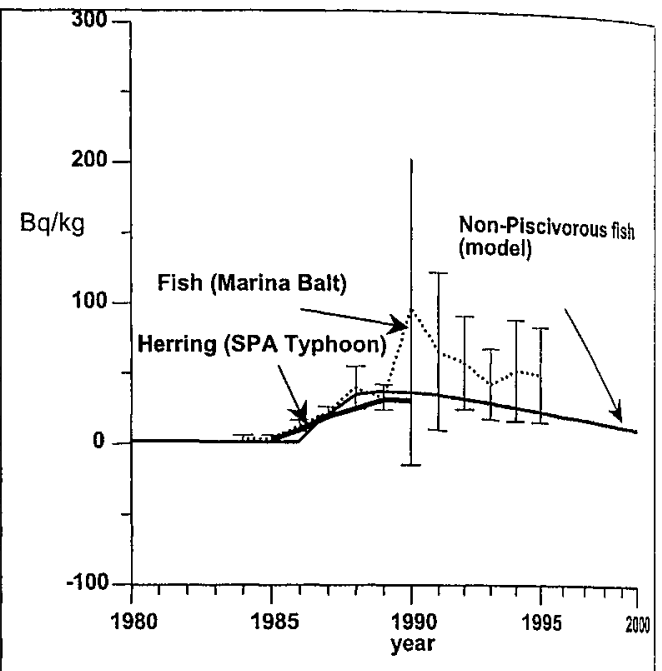

Figure 6 Bothnian Bay (box 37). Cs-137 Concentration in non-piscivorous fish. (Two-layered vertical structure, THREETOX exchange coefficients)

Figure 7 and 8 present the model results for the Black Sea (Black Sea West) for fish and molluscs respectively, using POSEIDON's standard value for the concentration factor phytoplankton of $5 \mathrm{~L} / \mathrm{kg}$.

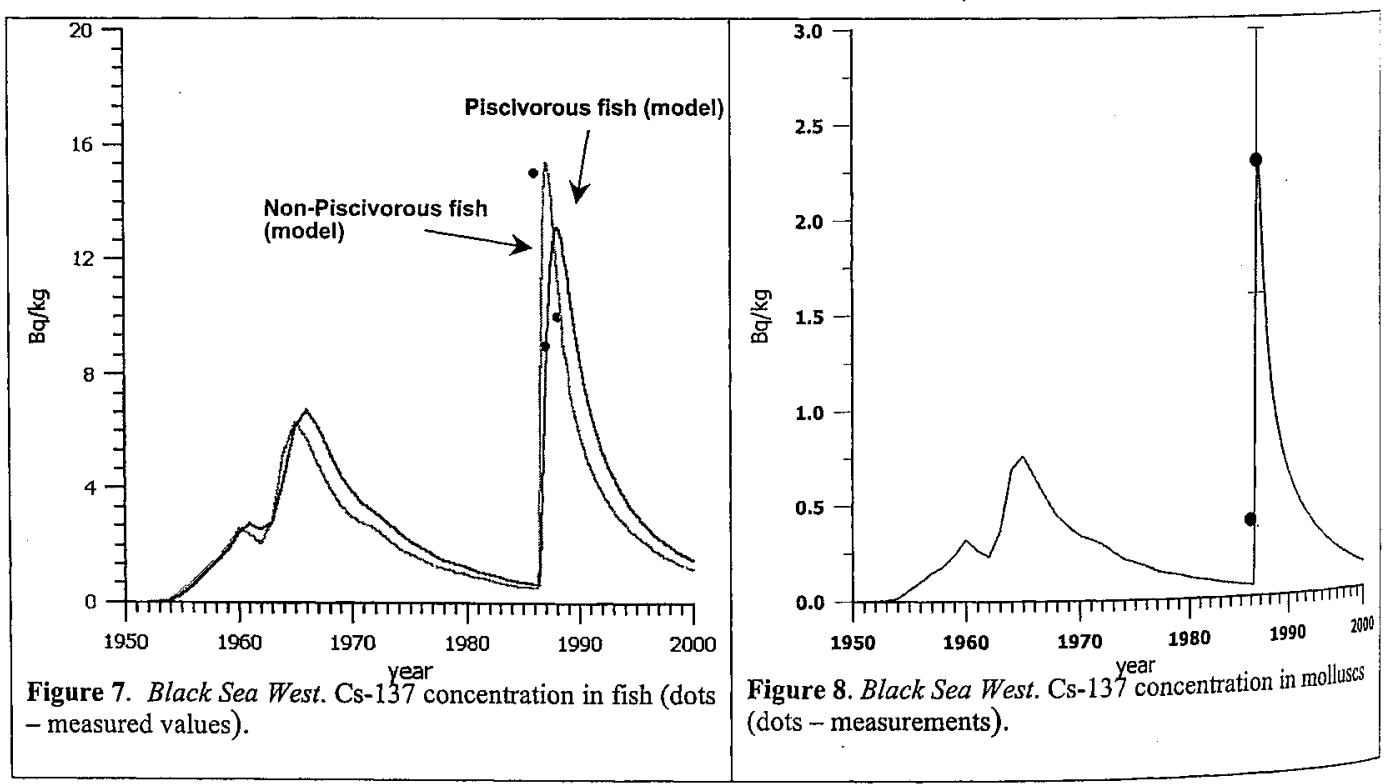




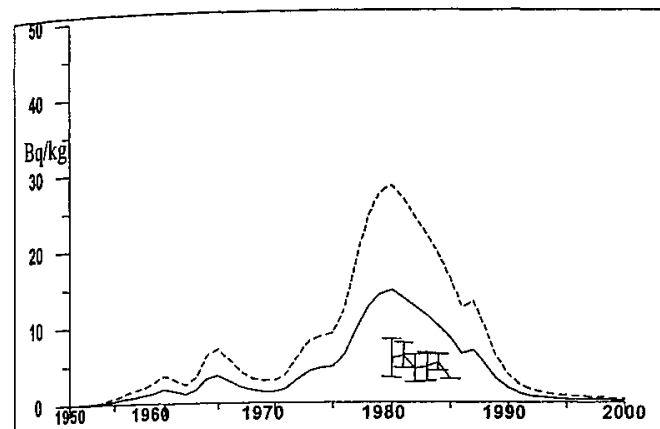

Figure 9 North Sea East (box 32). Predicted Cs-137 concentration in non-piscivorous fish. Solid line: $C F($ plankton $)=0.5 \mathrm{~L} / \mathrm{kg}$; dashed line: $\mathrm{CF}$ (plankton) $=5.0$ $\mathrm{L} / \mathrm{kg}$; line with error bars: measurements

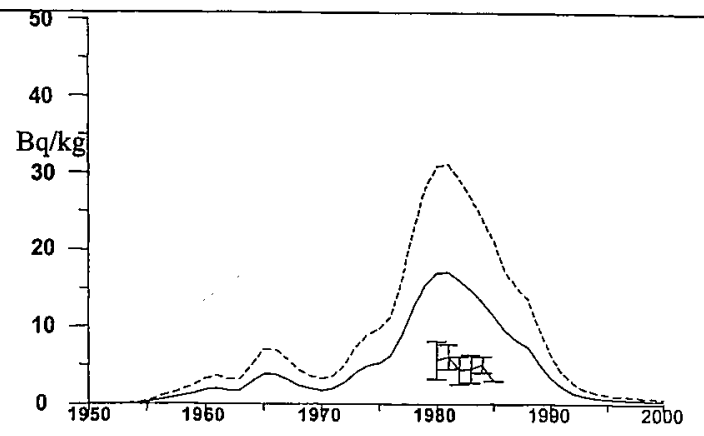

Figure 10 North Sea East (box 32). Predicted Cs-137 concentration in piscivorous fish. Solid line: $\mathrm{CF}$ (plankton) $=$ $0.5 \mathrm{~L} / \mathrm{kg}$; dashed line: $\mathrm{CF}$ (plankton) $=5.0 \mathrm{~L} / \mathrm{kg}$, line with error bars: measurements

Finally figure 9 and 10 present the model results for the North Sea (North Sea East) for non-piscivorous and piscivorous fish respectively, comparing POSEIDON's standard value for the concentration factor phytoplankton of $5 \mathrm{~L} / \mathrm{kg}$ with a lower value of $0.5 \mathrm{~L} / \mathrm{kg}$. For the lower $\mathrm{CF}$, the model overpredicts the measurements. This can be a consequence of the low uptake due to the high salinity, but also due to the migration of fish from other less contaminated areas to this compartment of the North Sea. For the use in POSEIDON a fixed of $5 \mathrm{~L} / \mathrm{kg}$ for all compartments is not unreasonable since overpredictions are not unacceptable in decision support systems such as POSEIDON. For testing the quality of BURN however a salinity-governed sub-model should be introduced.

\section{CONCLUSIONS}

The model results of the dynamical model of POSEIDON (BURN) demonstrate a sufficient agreement with the measurements for especially the brackish areas of the Baltic (Bothian Bay, Bothnian Sea, and Gulf of Finland). For the Black Sea the model results match with measurement of Cs-137 in fish and molluscs. The North Sea gave rather good results for the Cs-137 for fish. The variation of the Concentration Factor showed that the model was less sensitive for this parameter than envisaged. The dynamical model BURN is sufficient for modelling pulse releases in coastal regions, especially when the hydrological residence time of the compartment is shorter than the biological half-lives of the fish, and equilibrium is not reached. The dynamical model BURN enables the use of the POSEIDON model for accidental releases. Further validation test of the BURN model for are needed to verify the model's ablity to predict the behaviour of other radionuclides than radiocaesium. Tests to apply BURN on radiostrontium in the Black Sea are planned.

\section{Acknowledgements}

This paper is a result of the INCO Copernicus project IC15-CT98-0210. The paper reflects also the fruitful collaboration with the other project members V. Maderich (IMMSP Kiev), B. Veleva, and G. Mungov (NIMH, Bulgaria), and S. Lepicard (CEPN, France).

\section{REFERENCES}

[1] European Commission (1990). The Radiation Exposure of the Population of the European Community from Radioactivity in North European Marine Waters Project 'Marina', RP 47, EUR 12483.

[2] European Commission (1995) Methodology for Assessing the Radiological Consequences of Routine Release of Radionuclides to the Environment, RP 72, EUR 15760.

[3] Heling, R., M.Zheleznyak, W.Raskob, A.Popov, R.Borodin, D.Gofman, G.Lyashenko, A.Marinets, A.Pokhil, T.Shepeleva, and P.Tkalich. 1997. "Overview of the Modelling of Hydrological Pathways in RODOS", Radiation Protection Dosimentry. 73 (1-4) pp. 67-70

[4] Lepicard S., Raffestin D., Rancillac F., Radiation Protection Dosimetry, 75, (1998) pp 79-83. 
[5] R. Heling, S. Lepicard, V. Maderich,. V. Shershakov, G. Mungov, N. Catsaros, A. Popov. (2000). POSEIDON Final Report (1 October- 30 September 2000) IC15-CT98-0210. 15 November 2000. NRG Report no P26072/00.55075/P

[6] IAEA (1985); Sediment $\mathrm{K}_{\mathrm{ds}}$ and Concentration Factors for Radionuclides in the Marine Environment. Technical Report Series No. 247, International Atomic Energy Agency, Vienna.

[7] Coughtrey, P.J. Thorne, M.C., (1983). Radionuclide Distribution and transport in Terrestrial and Aquatic Ecosystems, A Critical Review of Data, Vol 1. A.A Balkema Amsterdam

[8] Nielsen S. P. Ed. (2000) The radiological exposure of the population of the European Community to radioactivity in the Baltic Sea. Marina-Balt project. EC-DG-ENVIRONMENT EUR - 19200 